\title{
Analysis of AC Breakdown Characteristics of Fly Ash Cenosphere/Epoxy Composite
}

\author{
Cheong-Won Seo*, Jung-Hun Kwon*, Young-Gwang Cha**, Su-Min Park** and Kee-Joe Lim ${ }^{\dagger}$
}

\begin{abstract}
In this study, AC breakdown properties of cenosphere/epoxy composite are investigated. The thermal properties of the composite are also discussed. The cenosphere/epoxy composites were prepared by epoxy resin filled with $0 \sim 40 \mathrm{wt} \%$ of hollow fly ash particles (cenospheres). The AC breakdown strength of the composites was measured at $25 \sim 125^{\circ} \mathrm{C}$. The permittivity, glass transition temperature, and coefficient of thermal linear expansion of the composites were also measured. The experimental results of the cenosphere/epoxy composite were compared with those of the silica/epoxy composite which are widely used as insulating materials in power apparatus. The cenosphere/epoxy composite showed the similar or better performance than silica/epoxy composite in terms of breakdown strength, glass transition temperature, and coefficient of thermal expansion.
\end{abstract}

Keywords: Cenosphere, Fly-ash, Epoxy-based composite, Eco-friendly, Breakdown, CTE, Tg

\section{Introduction}

The studies on the eco-friendly insulating materials have been carried out, as the restrictions on environmental contamination have increased due to global environmental pollution problems. However, it is not easy to change over to ecofriendly materials due to their lower performance compared to conventional insulating materials [1-4]. The fly ash cenosphere is one of byproducts of coal combustion at thermal power plants [5]. Cenospheres are typically hollow spherical particles with particle size of $10 \sim 600 \mu \mathrm{m}$, density of $0.3 \sim 0.6 \mathrm{~g} / \mathrm{cm}^{3}$, and shell wall thickness of $2 \sim$ $10 \mu \mathrm{m}$, which are composed of alumina, silica, calcium oxide, etc. [6, 7]. Cenospheres have been used in a wide variety of products, including fire- and heat-protection devices, and automobile bodies. Due to their special characteristics, they are primarily used as lightweight fillers. Their physical properties, particularly their low density (due to their hollow structure) and low thermal conductivity, make them popular as fillers for polymer compositions for structural materials [8-11]. With the increasing demand for compact and ecofriendly electrical equipment, several researches on the effect of cenosphere in polymer composites have investigated. Sharma et al. investigated the dielectric properties in cenosphere/LDPE composites and found that the dielectric constant decreased as cenosphere content increased [12]. Manjunath et al. investigated the possibility of cenospheres as fillers for cable insulation material and found that the mechanical and

$\dagger$ Corresponding Author: School of Electrical and Electronic Engineering, Chungbuk National University, Korea (kjlimg@gmail.com)

* School of Electrical and Electronic Engineering, Chungbuk National University, Korea. (bbqtt777@naver.com, endlessworld@cbnu.ac.kr)

**VVitzro Material R\&D center. ( $\{$ ykcha, psm $\} @$ vitzroeni.com)

Received: November 12, 2015; Accepted: May 11, 2016 thermal properties of cenosphere/PVC composite made it applicable to cable insulation material [10]. Deepthi et al. investigated the mechanical properties and thermal stability of surface treated cenosphere/HDPE composite and found improved mechanical and thermal properties [13]. However, studies on the electrical breakdown of cenosphere/epoxy composite are somewhat limited. In this study, the electrical breakdown strength and thermal properties of cenosphere/ epoxy composite are investigated. The breakdown strength is investigated in $25^{\circ} \mathrm{C}, 100^{\circ} \mathrm{C}, 125^{\circ} \mathrm{C}$. The properties of the composite are also compared to those of silica/epoxy composite.

\section{Experimental}

\subsection{Specimen preparation}

Fig. 1 shows an optical microscope photograph of the cenosphere and silica used in this study. The properties of cenosphere and silica used as filler are listed in Table 1. The composite specimens were consisted of base epoxy

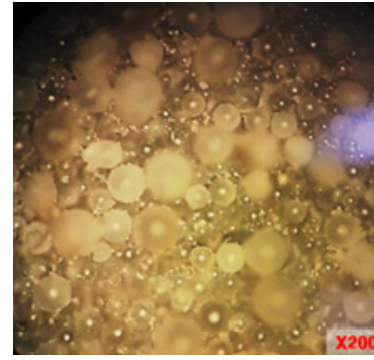

(a)

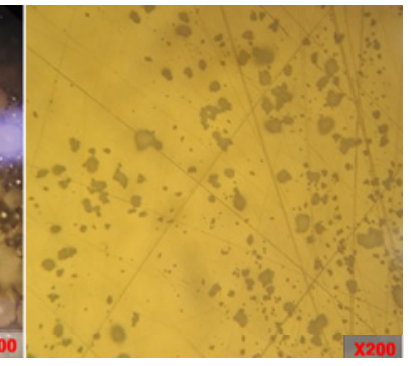

(b)
Fig. 1. Optical microscope photograph of particle shape; (a) Cenosphere and (b) Silica powder 
Table 1. Properties of cenosphere and silica

\begin{tabular}{ccc}
\hline & Cenosphere & Silica \\
\hline Particle [um] & $20 \sim 150$ & 20 \\
Specific gravity & 0.57 & 2 \\
Shape & Spherical & Irregular \\
\hline
\end{tabular}

Table 2. Properties of base resin

\begin{tabular}{ccc}
\hline & Resin & Hardener \\
\hline Specific gravity & $1.16( \pm 0.02)$ & $1.19( \pm 0.02)$ \\
Glass transition temperature $\left[{ }^{\circ} \mathrm{C}\right]$ & \multicolumn{2}{c}{$95-105$} \\
Breakdown strength $[\mathrm{kV} / \mathrm{mm}]$ & $>20$ \\
Permittivity & \multicolumn{2}{c}{$3-4$} \\
\hline
\end{tabular}

Table 3. Component of specimen

\begin{tabular}{cccc}
\hline Symbol & Resin & Filler type & Filler content $(\mathrm{wt} \%)$ \\
\hline EP0 & & - & 0 \\
SEP10 & Epoxy & Silica & 10 \\
SEP40 & (bisphenol-A, & & 40 \\
CEP10 & anhydrides) & Cenosphere & 10 \\
CEP40 & & & 40 \\
\hline
\end{tabular}

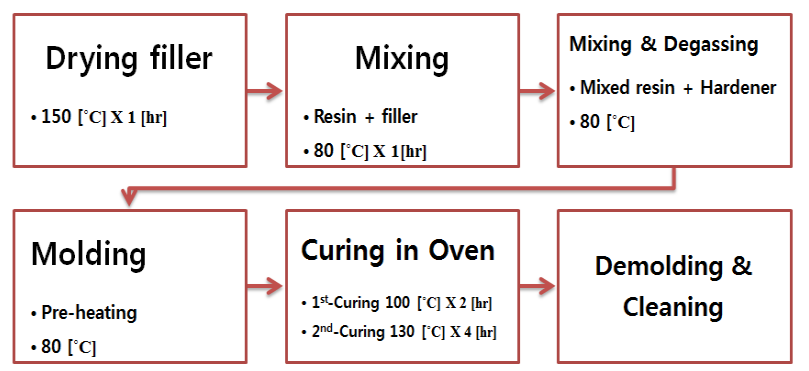

Fig. 2. Sample preparation process

resin (bisphenol-A), hardener (anhydrides), and filler as shown in Table 2 and Table 3. As shown in Table 3, this study has been performed on the five kinds of epoxy-based composites with different $\mathrm{wt} \%$ contents of silica or cenosphere filler. The filler particles were dried at $150^{\circ} \mathrm{C}$ for 1 hour before casting. Standard procedures for mixing, degassing, casting, and curing as recommended by epoxy manufacturers were used to prepare the samples as shown Fig. 2. The resin was mixed in a screw-type homogenizer at $2000 \mathrm{rpm}$ for about 1 hour at $80^{\circ} \mathrm{C}$. Thickness of the prepared specimen is about $1 \mathrm{~mm}$.

\subsection{Electrical breakdown and permittivity measure- ment}

The electrical breakdown strength under the AC field was measured according to IEC 60243-1. The voltage was increased at a rate of $1 \mathrm{kV} / \mathrm{s}$ until breakdown occurred. Fig. 3 shows the circuit schematic diagram used to measure the breakdown strength, which consists of AC high-voltage generator and a couple of spherical electrodes with diameter of $10 \mathrm{~mm}$. The breakdown strength was measured at $25^{\circ} \mathrm{C}, 100{ }^{\circ} \mathrm{C}$, and $125^{\circ} \mathrm{C}$. More than ten specimens were tested under the same conditions. The scale parameters in

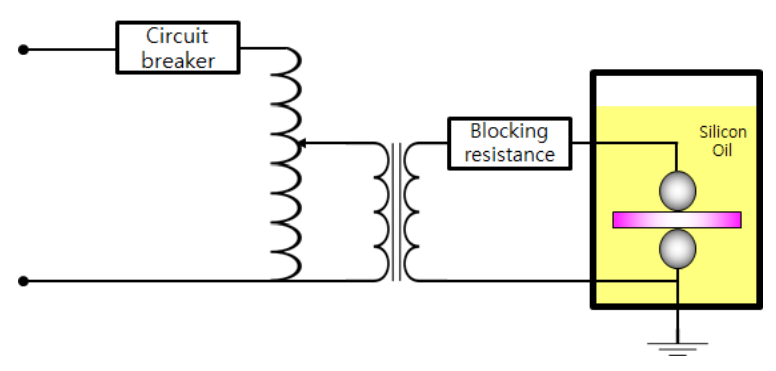

Fig. 3. Scheme of AC breakdown experimental setup

Weibull distribution from test data are fixed as the breakdown strength. It is well known that the decreases of breakdown strength of solid polymeric insulators are severe above glass transition temperature. The temperatures of all specimen were in the range of $100 \sim 110^{\circ} \mathrm{C}$, depending on a particular composition, as described later. The temperature ranges in breakdown test were selected by considering the glass transition temperature. The permittivity of specimens was measured by C \& tan delta meter (Tettex 2818, Tettex Co.) at room temperature under $1 \mathrm{kV}$.

\subsection{Thermal properties measurement}

The coefficient of thermal linear expansion (CTE) and glass transition temperature $(\mathrm{Tg})$ were measured using a Thermo-mechanical analyzer (TMA 2940, TA Instruments). A thermal scan of the specimen was run at a heating rate of $5^{\circ} \mathrm{C} / \mathrm{min}$ in the temperature range from 25 to $200^{\circ} \mathrm{C}$.

\section{Results and discussion}

\subsection{Breakdown strength and permittivity}

Fig. 4 shows the breakdown strength of each specimen at $25^{\circ} \mathrm{C}, 100^{\circ} \mathrm{C}$, and $125^{\circ} \mathrm{C}$. The breakdown strength of the specimens is decreased with increasing temperature. The results show a typical breakdown characteristic in high temperature region. The breakdown mechanism may be explained by thermal breakdown as considering the temperature dependency of breakdown strength and the time to breakdown (about 1sec.) together [14]. The decreasing rates of the breakdown strength with temperature above $100{ }^{\circ} \mathrm{C}$ are also depended on the glass transition temperature of samples as shown Fig. 4 and 7 . The decreasing rates are smaller in the higher glass transition temperature of samples. These facts may be explained by the increases of heat generation by the dielectric relaxation $\alpha$ loss above glass transition temperature. Fig. 4 also shows that the breakdown strength is decreased with increasing the $w t \%$ contents of fillers. These results are similar to the tendency of breakdown in traditional insulating epoxy composites filled with inorganic micro-particles.

The decreases of breakdown strength depending on $\mathrm{wt} \%$ contents of cenosphere are smaller than those of silica. For 


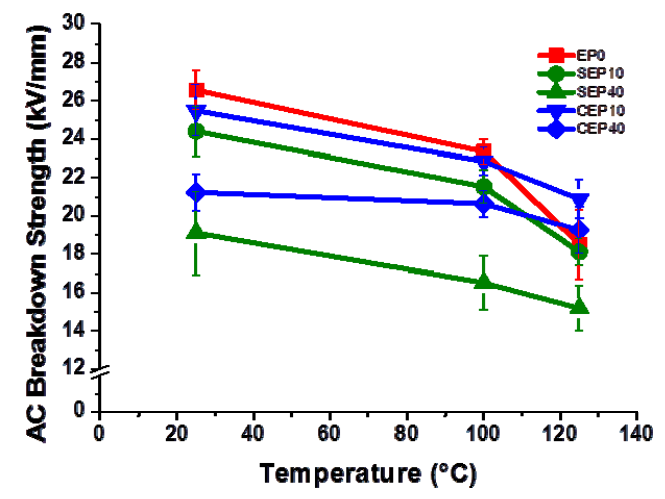

Fig. 4. AC breakdown strength of epoxy composite according to temperature

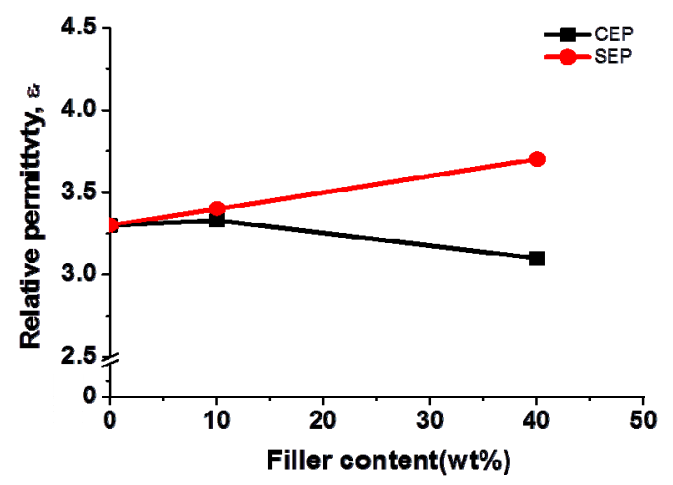

Fig. 5. Relative permittivity of epoxy composite

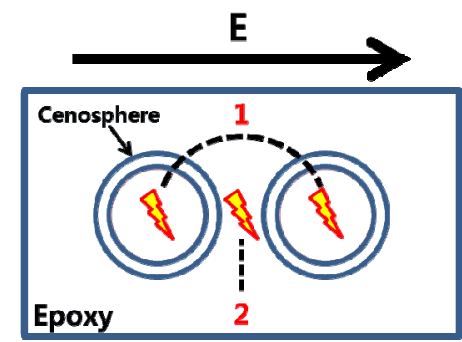

(a)

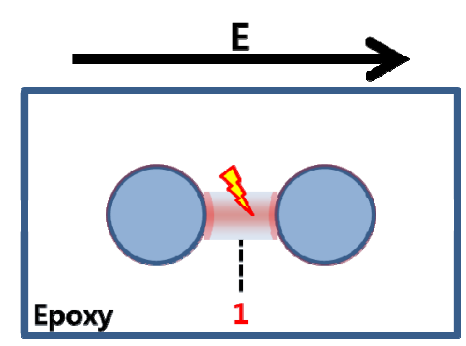

(b)

Fig. 6. Schematic of breakdown mechanism in resin: (a) hollow microsphere; (b) filled microsphere

specimens with the same contents of filler, cenosphere/ epoxy composite has higher breakdown strength than that of silica/epoxy composite at the experimental temperature ranges. These facts may be explained in terms of details of

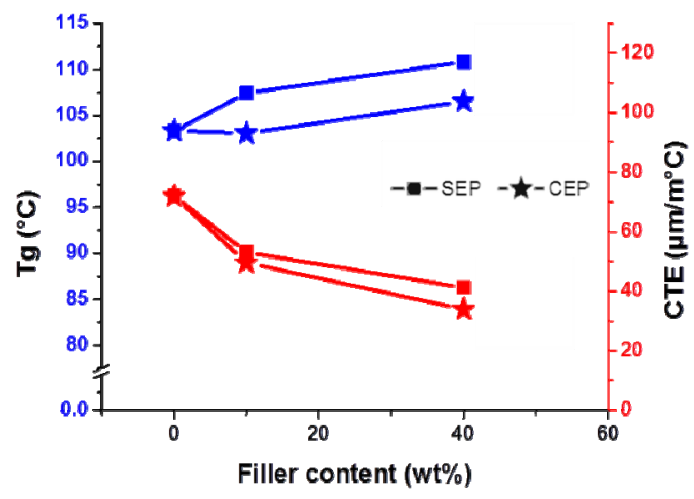

Fig. 7. Tg and CTE of epoxy composite

breakdown process as follows. In case of cenosphere/ epoxy composite, the gas discharge is firstly initiated inside hollow sphere of cenosphere particles by application of AC voltage, because the electrical stress is concentrated at the hollow part with lower permittivity. The gas discharges lead to the erosion of the microsphere walls followed by the breakdown of the whole material as shown Fig. 6(a) [16-17]. But the other hand, in case of silica/ epoxy composite, the AC field leads to an increase in the electrical field in the epoxy resin between adjacent micro silica particles followed by a breakdown of the whole material as shown Fig. 6(b). Strauchs et al. reported that the electrical breakdown was initiated by gas discharges inside the hollow sphere in the hollow microsphere under the AC field [18]. Anderson et al. also, reported that breakdown strength of glass micro-balloon was higher than conventional gas discharge criterion to the voids, because the deceases of triggering free electrons might reduce the rate of field emission or field ionization events [19-20]. The performance of breakdown of cenosphere/epoxy composites is better than that of silica/epoxy composites.

The relative permittivity of samples is shown in Fig. 5. The permittivity of cenosphere/epoxy composite depending on the content of filler is lower than that of silica/epoxy composites. The results may be explained by the MaxwellGarnett formula. It is needed to match permittivity for reducing the electric field concentration in practical hybrid insulation system. The lower permittivity insulators are also desirable in hybrid insulation system. In this standpoint, the cenosphere/epoxy shows better performance than silica/epoxy composite

\subsection{Thermal properties}

The measured results of the thermal properties are given in Fig. 7. The glass transition temperature, $\mathrm{Tg}$ of the specimen is increased as filler content is increased. This result may be explained by interaction between polymer matrix and surface of filled particles. Particles are caused to restrict the movement of the polymer chain in the polymer composite at increasing temperature, thus causing 
the Tg of the composite to increase. The coefficient of thermal linear expansion, CTE of the material is one of important properties. At practical application of epoxybased composite in power apparatus, a larger difference of CTE between metals and epoxy composite may cause to generate peeling off or imperfection at interface between two kinds of materials during heat cycle. An epoxy-based composite with smaller CTE is desired. The CTE of cenosphere/epoxy composite is smaller than that of silica/ epoxy composite.

\section{Conclusion}

In this investigation, the breakdown strength, permittivity, glass transition temperature, and coefficient of thermal linear expansion of fly ash cenosphere/epoxy composites were measured and discussed. The performances of the composite are also compared to those of conventional silica/epoxy composites. The electrical breakdown strength of cenosphere/epoxy composite is higher than that of silica/epoxy in the experimental temperature range. The decreases of breakdown strength of cenosphere/epoxy composite above $100^{\circ} \mathrm{C}$ are also smaller than those of silica/epoxy composite. These results may be explained by the details of breakdown process and glass transition temperature of specimen. As results of the Tg and CTE experiment, cenosphere/epoxy composite has similar or better thermo-mechanical performance than silica/epoxy composite. According to the above discussions, it is concluded that cenosphere can be considered as useful filler for epoxy-based insulation composite due to its electrical and thermo-mechanical properties. However, for practical application of cenosphere/epoxy composite as insulation in power equipment, further study is needed.

\section{Acknowledgements}

This work was supported by the research grant of Chungbuk National University in 2014.

\section{References}

[1] S. H. Nam and H. Kang, "Analysis on the Dielectric Characteristics of Dry Air According to Pressures for Developing an Eco-friendly High Voltage Switchgear", Trans. KIEE, Vol. 60, No. 8, pp. 1560-1565, Aug. 2011.

[2] K. Mardikyan, O. Kalenderli, O. Ersen, and E. Canarslan, "AC Breakdown Strength of N2, SF6 and a Mixtiure of N2+SF6 Containing a Small Amount of SF6", Conf. IEEE, pp.763-765, Jun. 1996.

[3] D. S. Kwag, "Breakdown Properties for Insulation Design of the Environment-Friendly Pole Trans- former using the Vegetable Insulating Oil”, KOSOS, Vol.26, No.6, pp.7-12, 2011.

[4] Y. G. Cha, "Breakdown Characteristics of PLA Nanocomposite for Eco-friendly Insulation", MS Thesis, Chungbuk National University, 2014. (in Korean)

[5] E. V. Fomenko, N. N. Anshits, M. V. Pankova, L. A. Solovyov, and A. G. Anshits, "Fly ash Cenosphere: Conposition Morphology, Structure, and Helium Permeability", WOCA Conf., May 2011.

[6] S. Torrey, "Coal Ash Utilization: Fly Ash Bottom Ash and Slag," Noyes Data, Park Ridge, 1978.

[7] Y. S. Kang and S. S. Kim, "Effect of Additive Ball Clay on Physical Properties of Porous Ceramic", JKSEE, Vol. 36, No. 2, pp. 109-112, Feb. 2014.

[8] P. Kadam, B. Pawar and S. Mhaske, "Studies in Effect of Low Concentration of Cenosphere on Mechanical, Thermal, Electrical, Crystallinity, Colorimetric and Morph.ological Properties of Epoxy Cured with Triethylenetetramine", JMMCE, pp.117-123, 2013.

[9] P. A. Wasekar, P. G. Kadam, and S. T. Mhaske, "Effect of Cenosphere Concentration on the Mechanical, Thermal, Rheological and Morphological Properties of Nylon 6", JMMCE, pp. 807-812, 2012.

[10] B.R. Manjunath, P. Sadasivamurthy, P.V. Reddy, and Karickal R. Haridas, "Studies on Cenospheres as Fillers for PVC Compounds for Applications in Electrical Cables", JAIC, Vol.86, No.1, pp.10-14, 2013.

[11] Kobayashi M, Nakamura T, Tamura J, Kokubo T, Kikutani T. "Viscoelastic, mechanical and thermal characterization of fly ash-filled ABS composites and comparison of fly ash surface treatments", Polym. Compos., 2012

[12] J. Sharma, N. Chand, and M. N. Bapat, "Effect of cenosphere on dielectric properties of low density polyethylene", Result in Physics, Vol. 2, pp. 26-33, 2012.

[13] M.V. Deepthi, M. Sharma, R. Sailaja, P. Anantha, P. Sampathkumaran, and S. Seetharamu, "Mechanical and thermal characteristics of high density polyethylene?fly ash Cenospheres composites", Mat. Design, Vol. 31, pp. 2051-2060, 2010.

[14] D. A. Seanor, "Electrical Properties of Polymer", 1982, pp. 327-331.

[15] R. Liao, F. Zhang, Y. Yuan, L. Yang, T. Liu, and C. Tang, "Preparation and Electrical Properties of Insulation Paper Composed of $\mathrm{SiO} 2$ Hollow Spheres", Energies, 5, pp. 2943-2951, Aug. 2012.

[16] R. A. Anderson, R. R. Lagasse, E. M. Russick, and J. L. Schroeder, "Effects of void size and gas content on electrical breakdown in lightweight, mechanically compliant, void-filled dielectrics", J. Appl. Phys., Vol. 91, No. 5, pp. 3205-3212, Mar. 2002.

[17] A. Strauchs, A. Mashkin, A. Schnettler, J. Podlazly, and B. Wandler, "The Impact of Electrical Field 
Stress on the Volume Conductivity of Syntactic Foam", IEEE Conf., San Diego, America, pp. 1-5, 2010.

[18] M. Kessler, C. Roggendorf, and A. Schnettler, "Behavior of Elastic Syntactic Foams under Impulse Voltage Stress", IEEE Conf., San Diego, America, pp. 1-4, Jun. 2010.

[19] D. Winkel, R. Puffer, and A. Schnettler, "Investigation of the Breakdown Process of Syntactic Foam under Lightning Impulse Stress at Liquid Nitrogen Temperature", Trans. IEEE, Vol. 22, No. 2, pp. 11341141, Apr. 2015.

[20] A. Strauchs, A. Mashkin, A. Schnettler, J. Podlazly, and B. Jensen, "Investigations on the Partial Discharge Behavior of Syntactic Foam under Uniform Field Stress", IEEE Conf., San Diego, America, pp. $1-5$, Jun. 2010.

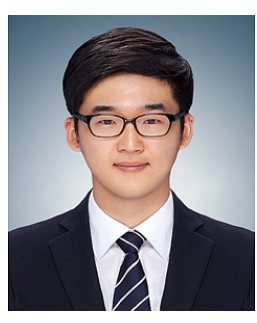

C. W. Seo He received a B.S degree in electrical engineering from Chungbuk National University, Korea. Currently he is a Master's student at the Department of Electrical Engineering, Chungbuk National University, Korea.

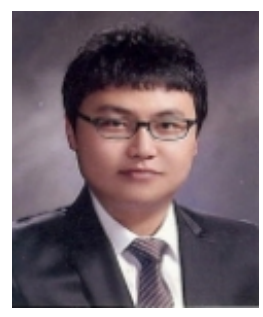

J. H. Kwon He received his B.S. and M.S. degree in 2011 and 2013 in electrical engineering from Chungbuk National University, Korea. Currently, he is a Ph.D. student at the Department of Electrical Engineering, Chungbuk National University, Korea.

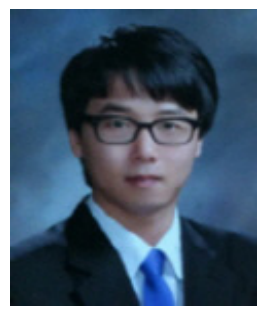

Y. G. Cha He received his B.S. and M.S. degree in 2011 and 2013 in electrical engineering from Chungbuk National University, Korea. Currently, he is a staff of R\&D center at the SPD PT at Vitzro Material, Korea.

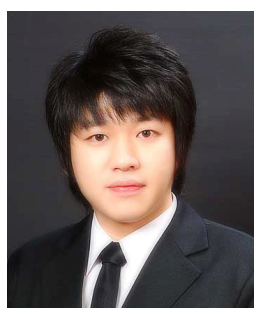

S. M. Park He received his B.S. degree in 2009 in electrical engineering from Dongyang Mirae University, Korea. Currently, he is an assistant manager of R\&D center at the SPD PT at Vitzro Material, Korea.

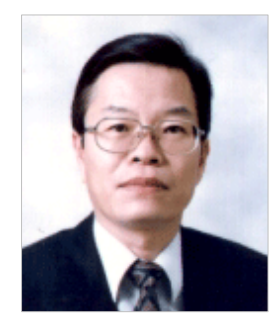

K. J. Lim He received B.S. M.S. and $\mathrm{Ph} . \mathrm{D}$. degrees from Han-Yang University, Seoul, Republic of Korea, in 1973, 1979 and 1986, respectively. He is currently a full professor at the Department of electrical engineering at Chungbuk National University, Korea. His research interests include electrical materials, high voltage techniques, piezoelectric ceramics, etc. 